\title{
Optimization of Aluminium Extrusion Process using Taguchi Method
}

\author{
A. S. Chahare, K. H. Inamdar \\ (Department of Mechanical Engineering, Walchand College of Engineering, Sangli, India)
}

\begin{abstract}
Direct hot extrusion of Al 6063 aluminium alloy was considered in this study to obtain the optimum process parameters for feature angularity of a two track top profile used in commercial window assembly. Taguchi design of experiments was used to analyze the experimental results and obtain the optimum process parameters using $s / n$ ratio analysis. Three factors (billet pre-heating temperature, container temperature and ram speed) with three levels each were used for performing the experiments to determine the response variable (feature angularity). Through analysis the optimum level of process parameters for feature angularity was obtained with billet pre-heating temperature of $500{ }^{\circ} \mathrm{C}$, container temperature of $400{ }^{\circ} \mathrm{C}$ and ram speed of 6.0 $\mathrm{mm} / \mathrm{sec}$. Analysis of variance was used to investigate the impact of process parameters on the feature angularity. It was found that ram speed has the maximum contribution with 59.83\% followed by container temperature and billet pre-heating temperature.
\end{abstract}

Keywords-Analysis of variance, Feature angularity, Process parameters, S/N ratio, Taguchi method,

\section{INTRODUCTION}

Extrusion is one of the major metal forming processes used in transforming the size and shape of the materials from the casts structure of an ingot to a useful product. Extrusion is a flexible manufacturing process, as a single extrusion press may be used for multiple materials and can produce infinite number of shapes by simply changing the die and the tooling associated with it. Aluminum is the most widely used material for extrusion process because of its considerable strength and also easily deformable properties. At present, the extrusion process parameters are selected on the basis of experience and the trial runs. Extrusion is a very complicated process which requires proper process parameters to be used to get optimum settings to produce a quality product. Therefore, most of the researchers are inclined towards the selection of optimum parameters which gives the best quality product.

Zhang et al. used Taguchi's Design of Experiments and $\mathrm{S} / \mathrm{N}$ analysis to obtain uniform flow distribution and to minimize the extrusion force in direct extrusion of A16063, which showed the maximum influence of billet diameter on velocity distribution and ram speed on extrusion force [1]. Reggiani et al. opted for multi-objective optimization of AA7003 by developing neural networks for various response parameters [2]. Hajeeh developed two optimization models for billet cutting patterns two minimize the scrap produced by using various dies in an aluminium industry [3]. Qamar et al. categorized various defects encountered in an aluminium industry and analyzed to identify the cost incurred in those categories [4]. Arif et al. conducted experiments to study the inter relationship between the ram speed, ram pressure and tool complexity for direct extrusion of Al6063 aluminium alloy [5]. Lucignano et al. developed two three layered artificial neural networks to predict the temperature profiles at the exit of the induction heater and die for direct extrusion of Al6060 alloy [6]. Hsiang et al. used fuzzy based Taguchi method to maximize flattening strength and T-slot fracture strength of magnesium alloy bicycle carriers [7]. Duan et al. used Taguchi method with FEM analysis to depict the influence of process parameters on the surface cracks of extruded aluminium alloy products [8]. Jawwad and Bashir used Design of Experiments to study the effect of process parameters on profile exit temperature of industrially extruded 6063 aluminium alloy and also developed statistical model for the prediction of profile exit temperature which has close resemblance with the measured values [9]. Arif et al. categorized the die failure mechanisms leading to defects in finally extruded product of $\mathrm{Al} 6063$ alloy by considering sixteen different die profiles and found major contributions of fatigue fracture, gradual wear and profile deflection for the failure mechanisms [10].

Optimization of process parameters for aluminium extrusion has gained significant importance to get improved quality of products. However, current research mainly focuses on simple solid section of window frame used for commercial purposes. In this paper, full factorial Design of Experiments is used to carry out the experiments to obtain response parameters. Twenty seven Experimental runs are performed to analyze the effect of process parameters (billet pre-heating temperature, container temperature and ram speed) on the response parameter (feature angularity). Extruded products are unique in that they have constant cross-sectional 
geometries throughout their lengths. Feature angularity is defined as the angle between adjacent features. Taguchi's signal to noise ratio is used to determine the optimum level of each process parameter for minimum angular deviation of the profile. Analysis of variance is performed on the obtained results to study the influence of process parameters on the response variable.

\section{EXPERIMENTAL WORK}

\subsection{Profile and Process Evaluation}

The experimental runs are performed by using a 900MT aluminium extrusion press present at Sangli Aluminium Extrusion Pvt. Ltd. on $\mathrm{Al} 6063$ aluminium alloy as shown in fig. 1. In this study, direct hot extrusion process is evaluated. The chemical composition of Al 6063 used for this study is shown in Table 1. In this paper, feature angularity of Two-Track Top profile used for sliding windows is considered for the experimental work. At the assembly stage feature angularity has a prominent role to fit and slide the parts over each other. Therefore, to minimize the angular deviation is a significant consideration for a quality product. Thus, the optimization of process parameters is an essential requirement to gain the minimum deviation in angularity.

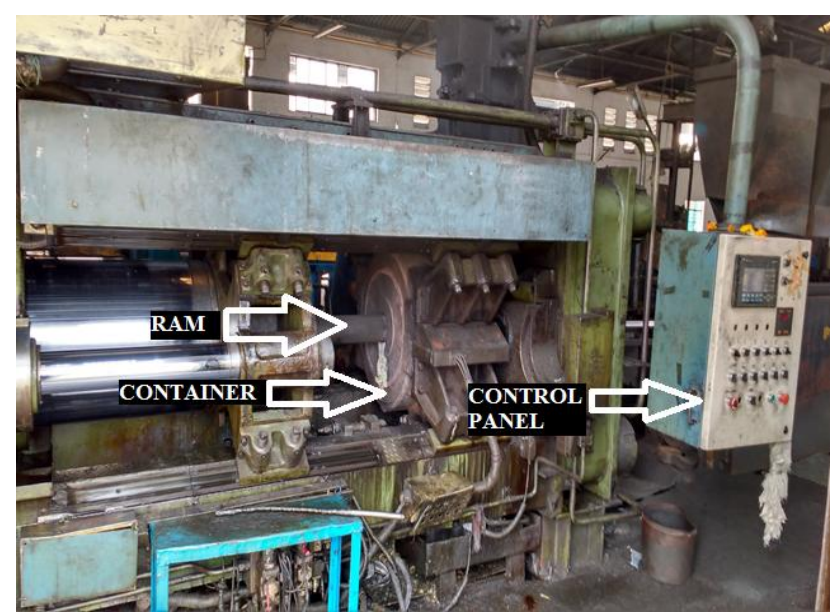

Fig. 1 Aluminium Extrusion Press (900 MT)

Fig. 2 shows the profile used for the experimental work and analysis. Fig. 2(a) shows the standard profile with dimensions required for the window assembly and Fig. 2(b) shows the original die profile, whereas Fig. 2(c) shows feature angularity $(\Theta)$ of the profile which is to be minimized. The thickness of the profile is $1.05 \mathrm{~mm}$ and the cross-section area of the profile is $222.6 \mathrm{~mm}^{2}$. In this paper, the signal to nose with smaller the better characteristic is used to find the optimum process parameters, which defined in equation (1) [11]:

$S N=-10 \log \left(\frac{1}{n} \sum_{i=1}^{n} y_{i}^{2}\right)$

Where $y_{i}$ is the response value obtained at $i^{\text {th }}$ experimental run and $n$ is the total number of experimental runs.

Table 1 Chemical composition of $\mathrm{Al} 6063$ alloy

\begin{tabular}{|l|l|l|l|l|l|l|l|l|l|}
\hline Element & $\mathrm{Al}$ & $\mathrm{Si}$ & $\mathrm{Fe}$ & $\mathrm{Cu}$ & $\mathrm{Mn}$ & $\mathrm{Mg}$ & $\mathrm{Cr}$ & $\mathrm{Zn}$ & $\mathrm{Ti}$ \\
\hline \% Composition & 98.6 & 0.42 & 0.19 & 0.03 & 0.02 & 0.65 & 0.02 & 0.06 & 0.01 \\
\hline
\end{tabular}

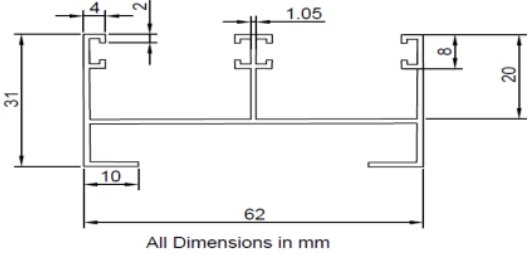

(a)

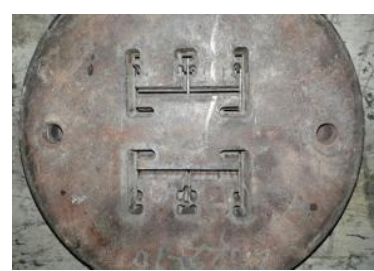

(b)

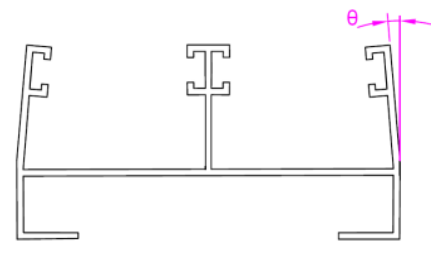

(c)

Fig. 2 two track bottom profile (a) standard profile, (b) Die Profile and (c) feature angularity 


\subsection{Process Parameters Selection}

Billet pre-heating temperature, container temperature and ram speed are the most influencing parameters during extrusion of aluminium alloys to obtain defect free and high quality of product with improved efficiency of the extrusion process. Homogenization of billet by pre-heating is an essential part of hot extrusion to reduce the geometrical deviation during extrusion process. High extrusion temperatures leads to increase in ductility of the alloy to reduce the force required for extrusion, whereas low extrusion temperature helps to achieve good geometrical tolerances. Therefore, there is a need to obtain an optimum heating temperature to achieve geometry as well as reduced force.

Ram speed is another major contributing factor required to achieve high production rate. High ram speed reduces the contact area leading to reduction in friction between the die and the billet and ultimately reducing the temperature variation due to friction. Thus, uniform temperature reduces the defects in the final product. On the other hand, low ram speed increases the time of contact and thus leading to temperature variation along the cross-section of the extruded profile. Therefore, optimum ram speed is to be achieved.

In this study, full factorial design of experiments was considered and Taguchi's signal to noise ratio analysis is performed using the response variables obtained from experimental runs to determine the optimum level of each process parameter. Billet pre-heating temperature, container temperature and ram speed were considered as the process parameters having three levels for each parameter to obtain the optimized value for response variable. Table 2 depicts the process parameters and their levels considered in this study.

Table 2 Process parameters and their levels

\begin{tabular}{|l|l|l|l|}
\hline Process Parameters & Level 1 & Level 2 & Level 3 \\
\hline Billet Pre-Heating Temperature $\left({ }^{0} \mathrm{C}\right)$ & 480 & 500 & 520 \\
\hline Container Temperature $\left({ }^{\circ} \mathrm{C}\right)$ & 400 & 410 & 425 \\
\hline Ram Speed $(\mathrm{mm} / \mathrm{sec})$ & 4.5 & 5.2 & 6.0 \\
\hline
\end{tabular}

\subsection{Design of Experiments and Analysis}

In this work, L27 full factorial array is used based on three factors and three levels for the experiments. Table 3 depicts the Design of Experiments using Taguchi's method and the response variables obtained for each experimental run performed. Signal to noise ratio analysis is performed using minitab 17 statistical software to determine the optimum level of parameters for the feature angularity $(\Theta)$ measured in degree. Main effect plots for $\mathrm{s} / \mathrm{n}$ ratio are used to depict the relationship between the process parameters and response variable. Also from the $\mathrm{s} / \mathrm{n}$ ratio plot, optimum levels of process parameters were determined.

Table 3 Design of experiments and feature angularity with $\mathrm{S} / \mathrm{N}$ ratio

\begin{tabular}{|c|c|c|c|c|c|}
\hline \multirow{2}{*}{$\begin{array}{l}\text { Experiment } \\
\text { No. }\end{array}$} & \multicolumn{3}{|l|}{ Process Parameters } & \multicolumn{2}{|l|}{ Response Parameter } \\
\hline & $\begin{array}{l}\text { Billet Pre-Heating } \\
\text { Temp }\left({ }^{\circ} \mathrm{C}\right)\end{array}$ & $\begin{array}{l}\text { Container } \\
\text { Temp }\left({ }^{0} \mathrm{C}\right)\end{array}$ & $\begin{array}{l}\text { Ram Speed } \\
(\mathrm{mm} / \mathrm{sec})\end{array}$ & $\begin{array}{l}\text { Feature Angularity } \Theta \\
\text { (Degree) }\end{array}$ & $\begin{array}{l}\mathrm{S} / \mathrm{N} \text { of feature } \\
\text { angularity } \Theta\end{array}$ \\
\hline 1 & 480 & 400 & 4.5 & 5.85 & -15.343 \\
\hline 2 & 480 & 400 & 5.2 & 4.15 & -12.361 \\
\hline 3 & 480 & 400 & 6.0 & 3.13 & -9.911 \\
\hline 4 & 480 & 410 & 4.5 & 6.83 & -16.688 \\
\hline 5 & 480 & 410 & 5.2 & 5.63 & -15.01 \\
\hline 6 & 480 & 410 & 6.0 & 3.63 & -11.198 \\
\hline 7 & 480 & 425 & 4.5 & 7.23 & -17.183 \\
\hline 8 & 480 & 425 & 5.2 & 5.91 & -15.437 \\
\hline 9 & 480 & 425 & 6.0 & 4.33 & -12.73 \\
\hline 10 & 500 & 400 & $4 . .5$ & 5.25 & -14.403 \\
\hline 11 & 500 & 400 & 5.2 & 3.38 & -10.578 \\
\hline 12 & 500 & 400 & 6.0 & 1.53 & -3.694 \\
\hline 13 & 500 & 410 & 4.5 & 6.17 & -15.806 \\
\hline 14 & 500 & 410 & 5.2 & 5.35 & -14.567 \\
\hline 15 & 500 & 410 & 6.0 & 3.35 & -10.5 \\
\hline 16 & 500 & 425 & 4.5 & 6.95 & -16.84 \\
\hline 17 & 500 & 425 & 5.2 & 5.36 & -14.583 \\
\hline 18 & 500 & 425 & 6.0 & 4.17 & -12.403 \\
\hline 19 & 520 & 400 & 4.5 & 6.33 & -16.028 \\
\hline 20 & 520 & 400 & 5.2 & 4.83 & -13.679 \\
\hline 21 & 520 & 400 & 6.0 & 3.57 & -11.053 \\
\hline 22 & 520 & 410 & 4.5 & 6.92 & -16.802 \\
\hline 23 & 520 & 410 & 5.2 & 5.83 & -15.314 \\
\hline 24 & 520 & 410 & 6.0 & 3.83 & -11.664 \\
\hline 25 & 520 & 425 & 4.5 & 8.75 & -18.84 \\
\hline 26 & 520 & 425 & 5.2 & 4.65 & -13.349 \\
\hline 27 & 520 & 425 & 6.0 & 6.33 & -16.028 \\
\hline
\end{tabular}




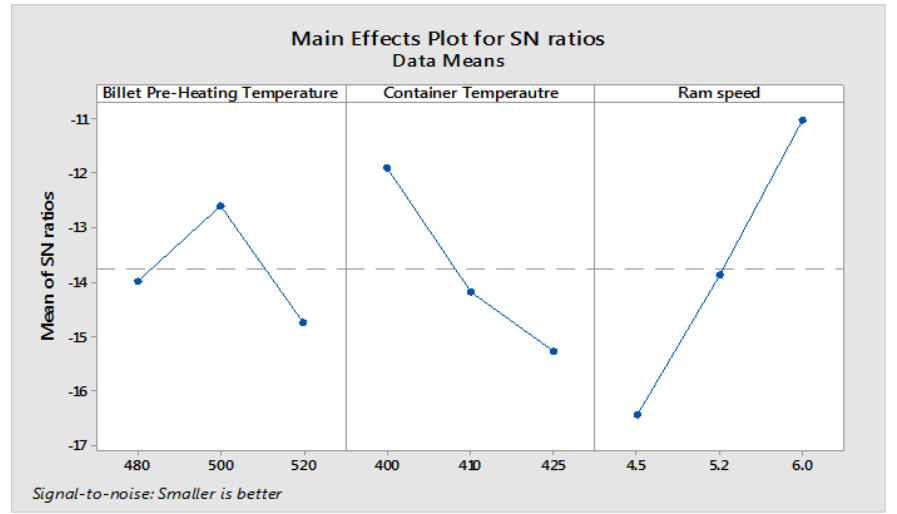

Fig. $3 \mathrm{~S} / \mathrm{N}$ ratio plots for feature angularity

Fig. 3 shows the $\mathrm{s} / \mathrm{n}$ ratio plots for the process parameters used for this study versus response variable (i.e. feature angularity). It is clear from the plots that ram speed has the maximum effect on the feature angularity. $\mathrm{S} / \mathrm{N}$ ratio plots shows the optimum process parameters for feature angularity as $500{ }^{\circ} \mathrm{C}$ of billet preheating temperature, $400{ }^{\circ} \mathrm{C}$ of container temperature and $6.0 \mathrm{~mm} / \mathrm{sec}$ of ram speed. Thus the optimum level of process parameters for feature angularity as the response parameter are determined using Taguchi's $s / \mathrm{n}$ ratio analysis.

\subsection{Analysis of Variance}

Analysis of variance is the most widely used statistical technique in the field of statistical inference and it is also the appropriate procedure for testing the equality of several means [12]. Analysis of variance confirms the amount of impact of process parameters on the response parameter. ANOVA is used in this study to determine the impact of considered process parameters on the feature angularity of an extruded profile. The ANOVA table for process parameters in shown in table 4 . For this model $95 \%$ confidence level is considered to confirm the experimental results.

Table 4 ANOVA results for feature angularity

\begin{tabular}{|l|l|l|l|l|l|l|}
\hline Source & DF & Sum of Squares & Mean Square & F value & P value & Contribution \\
\hline Billet Pre-Heating Temp. & 2 & 5.058 & 2.5292 & 6.91 & 0.005 & $7.75 \%$ \\
\hline Container Temp. & 2 & 13.836 & 6.9179 & 18.91 & 0.00015 & $21.20 \%$ \\
\hline Ram speed & 2 & 39.041 & 19.5206 & 53.36 & 0.000026 & $59.83 \%$ \\
\hline Error & 20 & 7.317 & 0.3658 & & & \\
\hline Total & 26 & & & & \\
\hline R Square $=88.79 \%$ & \multicolumn{5}{l|}{ R Square (adj) $=85.42 \%$} \\
\hline
\end{tabular}

Table 4 shows that the $\mathrm{p}$ value for all the process parameters are significant, as the $\mathrm{p}$ value is less than 0.05 . Also an inference can be drawn out from the $F$ values form the ANOVA table that $F$ value is greater than 2.49 from the $\mathrm{F}$ distribution table. The most contributing process parameter was ram speed with $59.83 \%$ followed by container temperature with contribution of $21.20 \%$. The least contributing factor is the billet preheating temperature with only $7.75 \%$. The $\mathrm{R}$ square value of $88.79 \%$ denotes that the process parameters considered in this study has the maximum influence on the feature angularity of the two track top profile, whereas R square value of $85.42 \%$ denotes that, there were very less chances of change in the optimum parameter levels for each process parameters.

\section{CONCLUSIONS}

In this paper, 27 experiments are performed using Taguchi's design of experiments by considering combination of three process parameters (billet pre-heating temperature, container temperature, and ram speed) at three levels to determine the feature angularity as response parameter for a two track top extruded profile. S/N ratio analysis is used to determine the optimum level of process parameters and ANOVA is used to investigate the impact of process parameters on the feature angularity.

a) Taguchi's design of experiments along with $\mathrm{s} / \mathrm{n}$ ratio analysis is used to determine the optimum level of process parameters. The optimum level of parameters determined using Taguchi's $\mathrm{s} / \mathrm{n}$ ratio analysis are billet pre-heating temperature at $500{ }^{\circ} \mathrm{C}$, container temperature at $400{ }^{\circ} \mathrm{C}$ and ram speed at $6.0 \mathrm{~mm} / \mathrm{sec}$.

b) The extent of impact of process parameters is determined by analysis of variance. From the ANOVA analysis it is clear that, ram speed had the maximum influence on the feature angularity with $59.83 \%$ contribution, whereas billet pre-heating temperature had the least impact with $7.75 \%$ contribution. 


\section{ACKNOWLEDGEMENT}

The authors acknowledge Sangli Aluminium Extrusion Private Limited to support for performing the experiments required for this work.

\section{REFERENCES}

[1] Cunsheng Zhang, Guoqun Zhao, Hao Chen, Yanjin Guan, and Hengkui Li, Optimization of an aluminium alloy extrusion process based on Taguchi's method with S/N Analysis, International Journal of Manufacturing Technology, 60, 2011, 589-599.

[2] Barbara Reggiani, Lorenzo Donati, and Luca Tomesani, Multi-ojective optimization of the extrusion process, Aluminium Two Thousand World Congress and International Conference on Extrusion and Benchmark, 2, 2015, 4847-4855.

[3] Mohammed Ali Hajeeh, Optimizing an aluminium extrusion process, Journal of Mathematics and Statistics, 9(2), 2013, 1549-3644.

[4] S. Z. Qamar, A. F. Arif, and A. K. Sheikh, Analysis of product defects in a typical aluminium extrusion facility, Journal of Materials and Manufacturing Processes, 19(3), 2007, 391-405.

[5] A. F. M. Arif, A. K. Sheikh, S. Z. Qamar, and K. M. Al-Fuahid, Variation of pressure with ram speed and die profile in hot extrusion of aluminium-6063, Journal of Materials and Manufacturing Processes, 16(5), 2007, 701-716.

[6] Carmine Lucignano, Robert Montanari, Vincenzo Tagliaferrri, and Nadla Ucciardello, Artificial neural networks to optimize the extrusion of an aluminium alloy, International Journal of Manufacturing, 21, 2010, 569-574.

[7] Su-Hai Hsiang, Yi-Wei Lin, and Jhong-Wei Lai, Application of fuzzy-based Taguchi method to the optimization of extrusion of magnesium alloy bicycle carriers, Internation Journal of Manufacturing. 23, 2012, 629-638.

[8] Xinjian Duan, X, Velay, and T. Sheppard, Application of finite element method in the hot extrusion of aluminium alloys, Journal of Material Science and Engineering, A369, 2004, 66-75.

[9] Abdul Kareem Abdul - Jawwad, and Adnan Bashir, A comprehensive model for predicting profile exit temperature of industrially extruded 6063 aluminium alloy, Journal of Materials and Manufacturing Processes 26(2), 2011, 193201.

[10] A. F. M. Arif, A. k. Sheikh, and S. Z. Qamar, A study of die failure mechanisms in aluminium extrusion, Journal of Materials Processing Technology, 134, 2003, 318-328.

[11] Philip J. Ross, Taguchi techniques for quality engineering (New Delhi, Tata McGraw-Hill, 2008).

[12] Douglas C. Montgomery, Design and analysis of experiments, (Arizona, John Willey and Sons, Inc., 2013). 